\title{
Medicine slow to recognize social media as window into the patient experience
}

\author{
- Cite as: CMAJ 2019 January 21;191:E87-8. doi: 10.1503/cmaj.109-5701
}

Posted on cmajnews.com on Dec. 19, 2018.

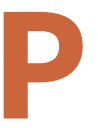

atients are increasingly turning to social media to vent their frustrations about health care, in some cases provoking backlash from doctors who feel attacked and unappreciated. But for those able to look past controversial hashtags, patients' angry tweets may hold crucial data for improving health care.

Recent trending hashtags, including \#DoctorsAreDickheads, \#MyDoctorSaid and \#HealthcareWhileColored, triggered an outpouring of stories on Twitter about doctors dismissing, misdiagnosing and mistreating patients. Many of the stories came from women, people with chronic or rare conditions, and others who felt their care had been compromised by prejudice.

One woman with multiple conditions wrote that doctors often assumed she was a drug addict when she complained about pain. "Doctors do not listen to me, 3 times over, for being a woman, black, disabled. I'm ignored, criminalized, infantilized."

Another wrote that she suffered from chronic and acute pain for two decades before she was diagnosed with a group of connective tissue disorders. "My right hip and shoulder dislocate on a daily basis. I have a dozen comorbidities. I was told it was my weight, anxiety or all in my head. It was undiagnosed EhlersDanlos syndrome."

Social media has given stories like these new reach and impact, says Dr. Matt Hawkins, an associate professor of pediatric radiology at Emory University in Atlanta. In the past, patients had few opportunities to connect and share their experiences, and limited recourse when unhappy with their care. But the balance of power has shifted as social media has enabled conversations

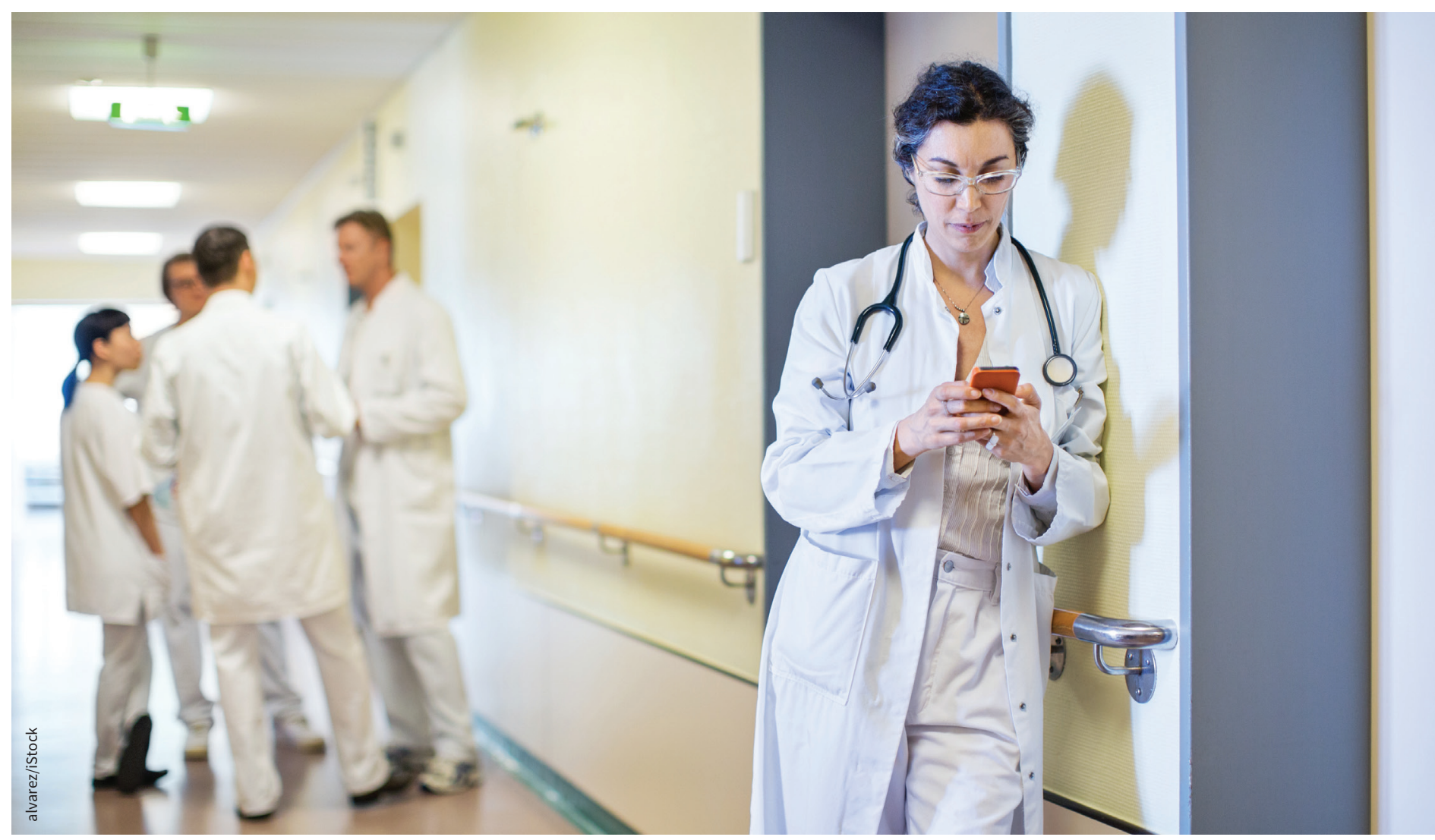

Doctors may not like it when patients complain about them on social media, but it could be viewed as valuable data on the patient experience. 
and comparisons across social and geographic divides.

Social media is also drawing new attention to blind spots in health care. "If you're seeing an area where patients seem to consistently express frustration, you can at least start to have something to guide what your next steps are if you want to continue to be a patient-centred organization," says Hawkins.

Other industries already use natural language processing and sentiment analysis technology to extract insights from social media about their products and services. Many major consumer brands use social media to crowdsource innovations and respond to customers' questions and complaints.

According to Dr. Ronen Rozenblum, an assistant professor at Harvard Medical School, health organizations have been slow to recognize the potential of social media as a window into the patient experience. However, that's starting to change. Most hospitals in the US have some presence on social media, and some have "crisis teams" that respond to online complaints and other threats to their reputations. In Canada, many hospitals use social media for branding and communication, but only lead adopters use it for patient engagement. The National
Health Service in England has gone a step further and actively monitors social media for trends in its performance.

Research on using social media data to measure patient satisfaction is still in its early stages. The big question is whether online comments reflect real-world quality of care, says Rozenblum. One American study he coauthored found a weak link between positive tweets and lower hospital readmission rates but no link between the sentiment of tweets and hospitals' performance in a nationally required patient satisfaction survey. Because many of the tweets discussed issues that were not covered by the survey, Rozenblum and his coauthors concluded that Twitter is a source of "potentially untapped feedback."

Patient satisfaction surveys have many strengths, says Rozenblum, but they only provide feedback on an aggregate level "months after the fact." Social media may not supplant surveys as a source of data on the patient experience, but it can add nuance and help organizations pinpoint and react to problems in real-time.

Rozenblum says both approaches have limitations. Surveys miss anyone who doesn't participate. Social media users tend to be younger and wealthier, although that's changing. Most people in the US who use the Internet use social media, including up to a third of seniors, according to Rozenblum.

Extracting useable data from social media remains difficult but will become easier as technology improves, he adds. And because social media is open to anyone, there's always a risk that people or organizations will game the conversation for their own interests.

There is also some resistance from health providers who see the growing empowerment of patients as a threat, says Rozenblum. Many doctors protested the blanket criticism of \#DoctorsAreDickheads and defended their profession under tags like \#DoctorsAreNotDickheads and \#DoctorsAreHuman. Some described the flood of patient complaints as an attack or bullying.

Doctors have traditionally had some control over their performance data, says Rozenblum. "We control the information that we're providing and reporting." But online, no punches are pulled.

"It's really exposed them, but they have to play the game," says Rozenblum. Ultimately, "this is where we're going, this is where patients and families are going, and this is where the health system is going."

\section{Lauren Vogel, CMAJ}

